\title{
Comparative Anatomy and Facial Aging in the Animal Kingdom
}

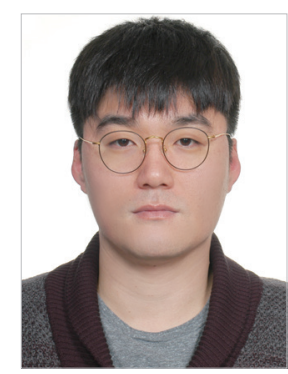

\author{
Aram Harijan, Seong-Yun Ha
}

Well Plastic Surgery Clinic, Seoul, Korea

\section{INTRODUCTION}

Since the beginning of modern plastic surgery discipline, facial aging has been a significant interest to plastic surgeons. One turning point for aesthetic surgery was the recognition that facial aging is more than skin deep and that any attempts at facial rejuvenation must address the subcutaneous connective tissue (i.e., fat, fascia, and muscle) [1-3]. Having been exposed to Tord Skoog's presentation and the 1969 publication, two surgeons from the Tessier group published the now-famous cadaveric study on the superficial fascia of the face, which was popularized under the term superficial muscular and aponeurotic system [4]. Subsequent to this, plastic surgeons began to abandon simple rhytidectomy procedures but instead developed a wide variety of techniques by which the deeper connective tissue is mobilized to restore a more youthful contour to the face.

Outside of the plastic surgery literature, a different discipline has been interested in the convergence and divergence in the anatomy and functions of the facial muscle. While the nature of facial soft tissues interested plastic surgeons because of potential applications in aesthetic and reconstructive operations, biologists and comparative anatomists were more interested in what similarities and differences could be observed across facial structures of various animals because these similarities and differences were helpful in understanding the evolution of muscles innervated by the seventh cranial nerve (CN-VII).

In this editorial, we would like to review the non-plastic surgery literature on the evolution of facial muscle (CN-VII muscles) and question again the nature of facial aging.

\section{ORIGIN OF FACIAL MUSCLES}

Early in the course of our medical education, we learn that the mandible forms from the first branchial arch and that facial muscles originate from the second branchial arch, without understanding what branchial arches really are. Most surgeons recognize branchial arches as embryologic structures that give rise to various head and neck tissues - the ontogenic branchial arch (Fig. 1). However, standard medical education does not touch upon the phylogenic origin of the branchial arches from fish gills.

The evolutionary process that eventually gave rise to branchial arches - and consequently facial muscles-begins with fish. The first of branchial arches arose from the jawless fishes (akin to the lamprey) approximately 500 million years ago. The cartilage of the first gill became the mandible in jawed fishes (Meckel's cartilage), and ossification of this jaw led to the wide spectrum of jawbones observed in most vertebrate animals. Concomitantly, this same process has led to the development of the fifth cranial nerve and masticatory muscles from the first arch. The shift of the first gill into the mandible was the transition between jawless to jawed fishes.

From the jawed fish, the second branchial arch rose to structures that separated the face from the anterior neck. It is at this point the constrictor muscles of second arch began the metamorphosis towards becoming facial muscles in mammals.

\section{FROM GILL TO NECK CONSTRICTOR MUSCLE}

The evolutionary path which transformed branchial arches from 


\section{Fig. 1. Branchial arch of human embryo at 13 weeks}

Each arch is composed of central mesenchymal unit (muscle and cartilage), accompanied by an artery and a cranial nerve (Illustration by Loki austanfell, https://commons.wikimedia.org/wiki/ File:PharyngealArchHuman.jpg).

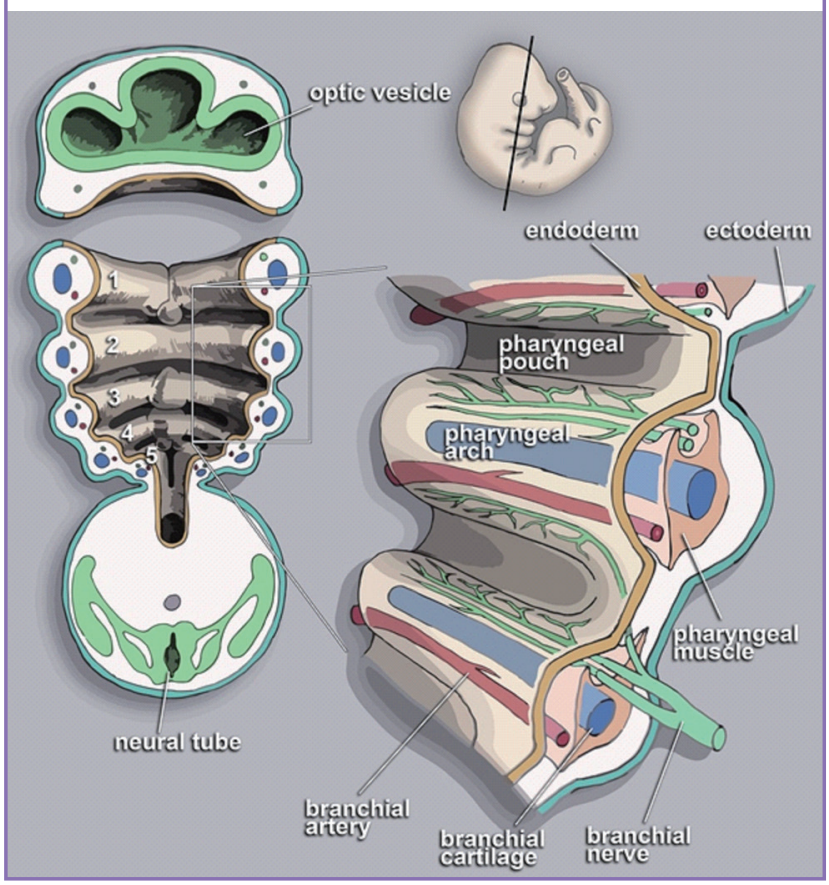

gill to facial muscle is a complex one. Whereas the first gill arch gave rise to masticatory muscles (innervated by the trigeminal nerve, $\mathrm{CN}-\mathrm{V}$ ), the second arch gave rise to constrictor muscles posterior to the jawbone, which eventually became part of the neck. Hence, this arch muscle of interest came to be called Sphincter colli (i.e., neck constrictor) in ectothermic vertebrates with jaws (i.e., fish, amphibians, and reptiles). Because of this, the first of "real" gill arches actually originate from the third branchial arch in fully developed fish (Fig. 2).

With landward migration, the ancestors to amphibians and all other land vertebrates required a physiologic mechanism by which oxygen and carbon dioxide is exchanged directly between the blood and the atmosphere, as opposed to that of gills. Development of the lung allowed for permanent lifecycle without the need for an embryologic phase in an aquatic environment [5]. Because the gills were no longer needed, the components of the branchial arch were no longer under selective pressure, and this allowed metamorphosis and specialization of the branchial cartilages and muscles.

In reptiles, the sphincter colli has insertions into the skin along the length of the neck, and the ventral portion of this tubular muscle is extremely similar to the platysma muscle of mammals, in both anatomy and histology $[6,7]$.

\section{Fig. 2. Branchial arch in embryologic fish}

The muscle of second branchial gill (red) are located between the mandibular arch (Meckel's cartilage) and the hyoid arch (Reichert's cartilage). Here, the first gill arch is actually the third embryologic arch (after the mandible and hyoid arches) (Illustration modified from p.139 of Huber, Part I. Public domain).

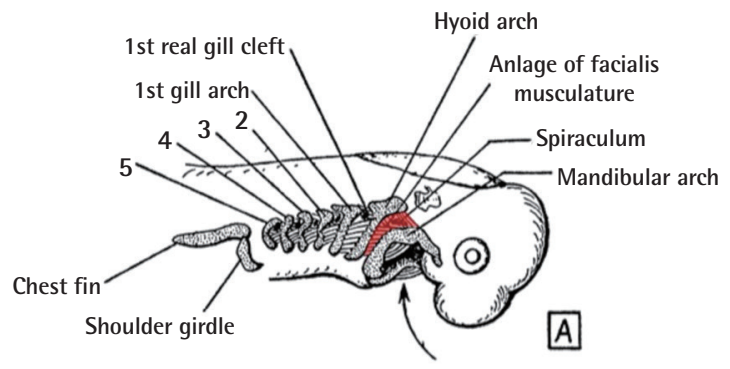

\section{SOFT-TISSUE AGING IN REPTILES}

One particular interesting model of aging can be found in those long-lived tortoises from the Galápagos Islands. These animals are known to live for more than 100 years in the wild, with captive examples having lived for 170 years. In these tortoises, the facial skin is adhered to the underlying bones, which are together considered as a single complex of dermatocrainum that gives the impression of the mask-like faces so easily identified with all reptiles. For the most part, morphology of the facial soft tissue does not change with age in these animals.

The skin overlying the neck, however, is not directly connected to any underlying bone, and the morphology of the soft tissue appears to reflect the status of the underlying Sphincter colli muscle (Fig. 3). It may be that older tortoises experience soft-tissue aging similar to that observed for aging platysma in humans.

\section{THE MAMMALIAN FACE}

Even in "early" examples of mammals like platypus, the dorsal portion of the Sphincter colli can no longer be found (Fig. 4). In its stead, the muscles of second gill arch has radiated from the nuchal area into the anterior face. Though seventh cranial nerve is present in most land vertebrates, the muscles innervated by this nerve is in the face only in mammals, and the seventh cranial nerve is called facial nerve only when describing mammalian anatomy $[6,7]$.

A number of studies have compared static anatomy of facial muscles, with detailed description of phylogenic relationship between homologous muscles across the vertebrate phylum. Such studies provide important evidences for craniofacial evolution in primates and hominid species [8]. Yet, facial aging itself has been studied mostly for humans whose operations have been 


\section{Fig. 3. Sphincter colli muscle in reptiles}

(A) The neck constrictor muscle (Sphincter colli; in red) originates from the second branchial arch, and forms the superficial layer of skin-attaching muscles. (B) Galápagos tortoises are known to life beyond 100 years, with differential aging evident between the face and cervical soft tissues (Illustration from p.141 of Huber, Part I. Public domain; Photograph modified from Matthew Field).

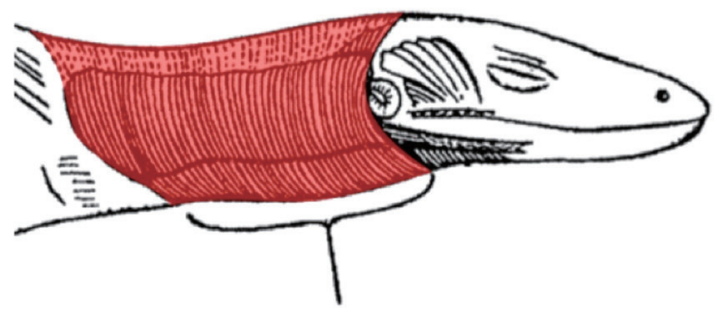

Superficial facialis musculature

[Sphincter colli]

(A)

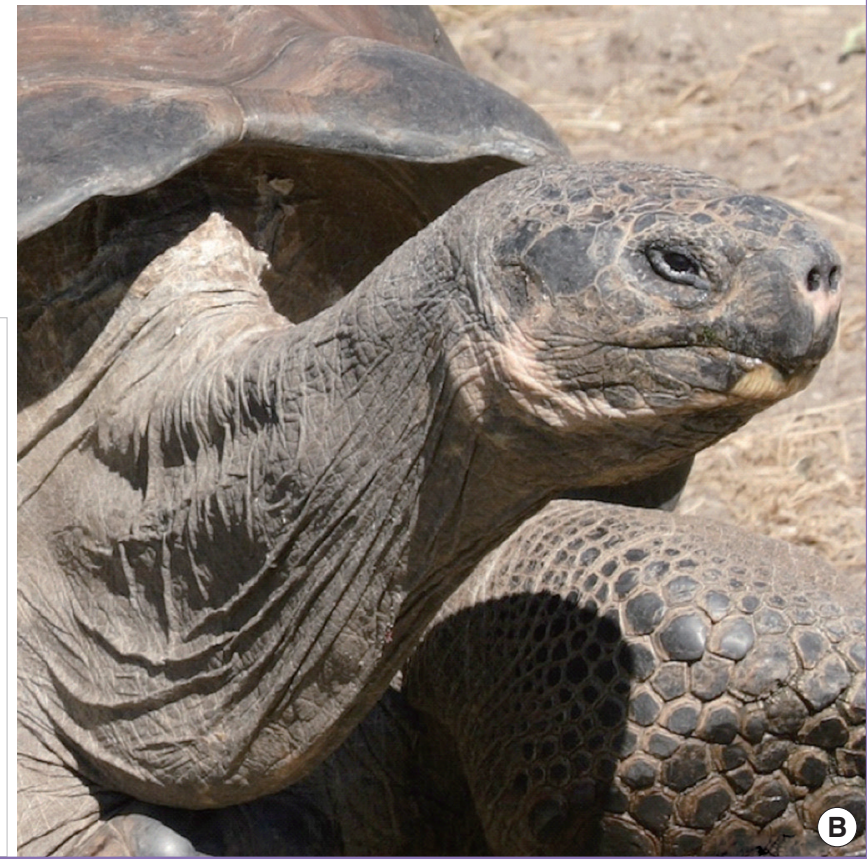

Fig. 4. Facial muscle in mammals

In platypus, the ventral portion of sphincter colli (red) still attaches to cervical dermis, as in reptiles and amphibians. However, the dorsal portion of sphincter colli muscle cannot be observed in mammals and, in its stead, the facial muscles can be found in complex organization (blue) (Modified from p.143 of Huber, Part I. Public domain).

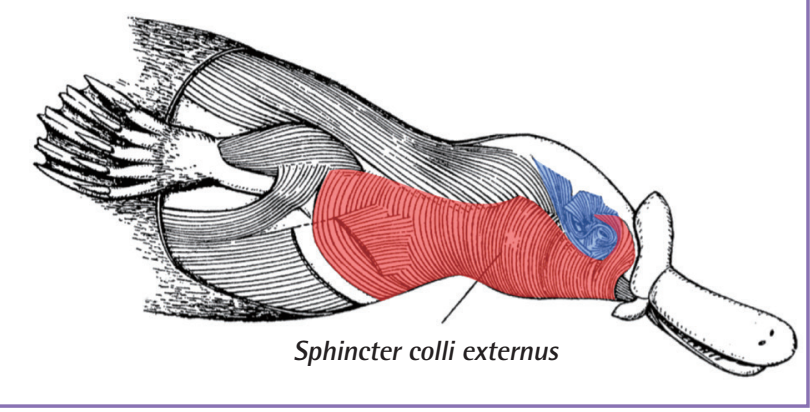

modified for domesticated animals $[9,10]$. Given adequate transdisciplinary cooperation between veterinary and plastic surgeons, theories on facial aging can be tested by comparing the process of aging in various animals, for which anatomy of the facial muscle is well understood.

\section{MAMMALS WITHOUT FACIAL AGING}

In whales and dolphins, facial muscle is largely absent. The single largest component of the facial soft tissue is the thick subcu-
Fig. 5. Facial muscles and aging in dolphin

(A) In cetaceans, facial muscles are not significant anatomic features except for those muscles used for controlling blowhole aperture. Most of the facial soft tissue is composed of a thick layer of subcutaneous fat, AKA blubber. (B) Faces of dolphins do not show signs of aging, with very few creases found in the facial skin proper (Modified from p.187 of Huber, Part I. Public domain. Photograph from MaxTab).
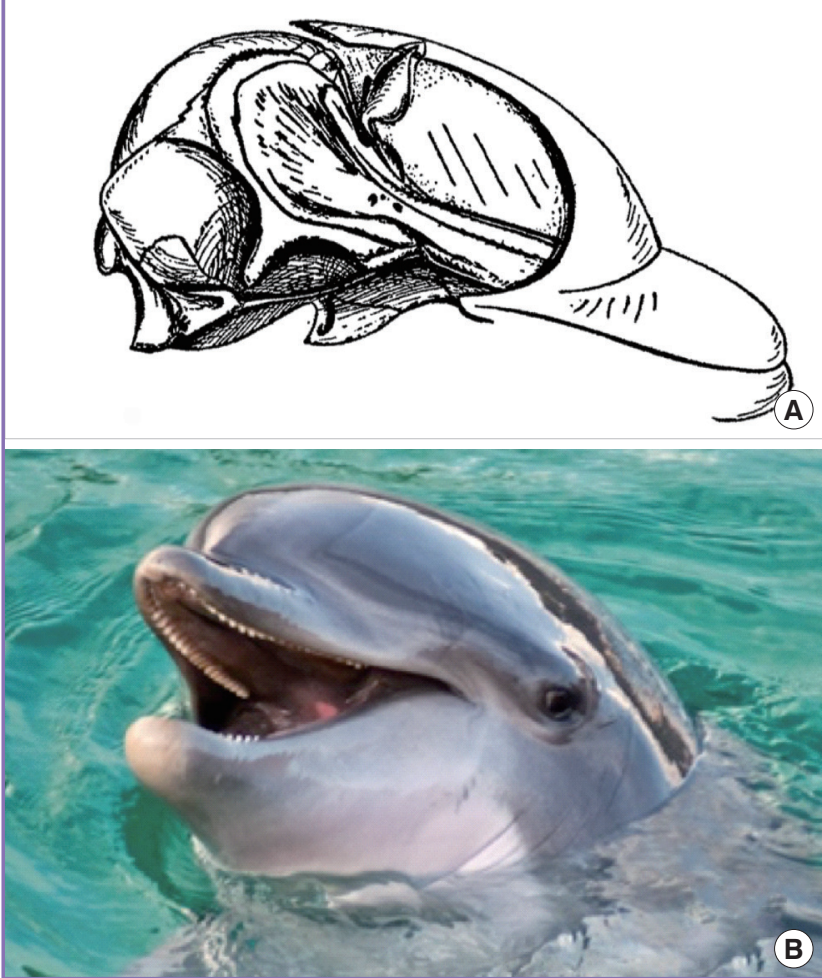
taneous tissue (i.e., blubber), and most of the facial skin is not attached to any facial muscle (Fig. 5). In dolphins, the facial nerve is exclusively dedicated to controlling muscles surrounding the blowhole, which is required for keeping the water out of the respiratory system and also for sound production $[11,12]$.

Sagging soft-tissue is not a consequence of aging for whales and dolphins. Coincidental to the absence of facial muscles, captive examples of cetaceans that live to be 'old' show very little signs of facial aging, such as pseudoherniation of fat tissues or deep skin creases.

\section{CONCLUSIONS}

Comparative anatomy of the second branchial arch tissues has shown phylogenic relationship of facial muscles and their precursor in reptiles and fishes. Across the vertebrate phylum, facial aging is a process unique to those mammals with extensively developed facial muscles. Where facial muscle is absent, facial aging appears to be absent-in and out of mammalian examples. Studies on facial aging should focus not only on superficial fascia but also address the changes that occur in aging facial muscles.

\section{REFERENCES}

1. Pangman WJ 2nd, Wallace RM. Cosmetic surgery of the face and neck. Plast Reconstr Surg Transplant Bull 1961;27:54450.

2. Conley JJ. Face-lift operation. Springfield: Thomas; 1968.

3. Skoog TG. Plastic surgery : new methods and refinements. Philadelphia: Saunders; 1974.

4. Zimbler MS. Tord skoog: face-lift innovator. Arch Facial Plast Surg 2001;3:63.
5. Perry SF, Sander M. Reconstructing the evolution of the respiratory apparatus in tetrapods. Respir Physiol Neurobiol 2004;144:125-39.

6. Huber E. Evolution of facial musculature and cutaneous field of trigeminus. Part I. Q Rev Biol 1930;5:133-88.

7. Huber E. Evolution of facial musculature and cutaneous field of trigeminus. Part II. QRev Biol 1930;5:389-437.

8. Kardong KV. Vertebrates: comparative anatomy, function, evolution. Boston: McGraw-Hill Higher Education; 2009.

9. Bedford PGC. Surgical correction of facial droop in the English cocker spaniel. J Small Anim Pract 1990;31:255-8.

10. McCallum P, Welser J. Coronal rhytidectomy in conjunction with deep plane walking sutures, modified Hotz-Celsus and lateral canthoplasty procedure in a dog with excessive brow droop. Vet Ophthalmol 2004;7:376-9.

11. Langworthy OR. A description of the central nervous system of the porpoise (Tursiops truncatus). J Comp Neurol 1932;54:437-99.

12. Huggenberger S, Rauschmann MA, Oelschlager HH. Functional morphology of the hyolaryngeal complex of the harbor porpoise (Phocoena phocoena): implications for its role in sound production and respiration. Anat Rec (Hoboken) 2008;291:1262-70.

Correspondence: Aram Harijan

Well Plastic Surgery Clinic, 1st Avenue building, 5th floor, 104 Dosan-daero, Gangnam-gu, Seoul 06038, Korea

Tel: +82-10-2040-7169, E-mail: aramkim80@gmail.com

No potential conflict of interest relevant to this article was reported.

Received: 11 Apr $2016 \bullet$ Revised: 13 Apr 2016• Accepted: 13 Apr 2016

pISSN: 2234-6163・ eISSN: 2234-6171

http://dx.doi.org/10.5999/aps.2016.43.3.225 • Arch Plast Surg 2016;43:225-228 